\title{
Humidity preference for fungus culturing by workers of the leaf-cutting ant Atta sexdens rubropilosa
}

\author{
F. Roces and C. Kleineidam \\ Zoologie II, Biozentrum der Universität Würzburg, Am Hubland, D-97074Würzburg, Germany, e-mail: roces@biozentrum.uni-wuerzburg.de
}

\begin{abstract}
Summary. The hygropreference of gardening workers of the leaf-cutting ant Atta sexdens rubropilosa was investigated in the laboratory using a gradient of relative humidity. Gardening workers were placed, together with pieces of fungus garden, in small, interconnected nest chambers offering four different relative humidities: $33 \%, 75 \%, 84 \%$ and $98 \%$ RH. Workers were allowed to move freely between them and to relocate the fungus following their humidity preference. While workers distributed themselves randomly in the nest chambers, they located the fungus gardens in the chamber with the highest humidity. These results indicate that gardening workers are able to sense differences in relative humidity, and that this ability is shown when they are engaged in fungus culturing. Humidity is discussed as one of the relevant variables that probably underlay the evolution of regulatory responses for the control of fungus growth in leaf-cutting ants.
\end{abstract}

Key words: Leaf-cutting ants, humidity, fungus culturing, nest climate, choice.

\section{Introduction}

In ant societies, the selection of suitable microclimatic conditions for brood rearing is an ubiquitous and significant activity. This is accomplished by nurse workers that, following their preferences, select appropriate places within the nest to which the immobile brood is transported (Roces and Núñez, 1995). In several ant species, the nest architecture helps to stabilize fluctuations of temperature and humidity, thus preventing a more or less continuous brood transport as these environmental variables change. Hence, brood transport inside the nest represents a fine-tuning response to cope with excessive deviations from the expected values.

Leaf-cutting ants of the genus Atta construct very large nests that house up to five million individuals and may contain more than 1000 chambers, one half of them filled with fungus gardens (Autuori, 1942). The symbiotic fungus has strict demands of high humidity and temperatures between 25 and $30^{\circ} \mathrm{C}$ for proper growth (Quinlan and Cherrett, 1978; Powell and Stradling, 1986). The fungus garden represents the sole food source for the developing larvae. Consequently, workers are expected to maximize fungus growth not only by the selection of appropriate vegetal substrate, but also by an active choice of suitable places for culturing according to the prevailing microclimatic conditions in the nest. Beside brood transport, workers may therefore be able to relocate the fungus gardens in order to provide them with the most appropriate environment inside the nest.

In the present study, gardening workers from a laboratory colony of Atta sexdens rubropilosa were confronted with a humidity gradient under constant temperature conditions. The workers' ability to distinguish different humidities and to relocate fungus gardens according to their humidity demands was evaluated.

\section{Materials and methods}

After the establishment of a humidity gradient in different nest chambers of a laboratory colony, both the humidity preference of workers and their preference to locate the fungus gardens were investigated. The test chambers were constructed using 4 small plastic Petri dishes $(5 \mathrm{~cm}$ in diameter) interconnected via a $2 \mathrm{~cm}$-long tygon tubing ( $1 \mathrm{~cm}$ in internal diameter). The base of each dish was cut and covered with nylon gauze. Defined humidities inside each chamber were established by placing other dishes containing different saline solutions beneath the gauze. We used the following saturated saline solutions: $\mathrm{K}_{2} \mathrm{Cr}_{2} \mathrm{O}_{7}$ for $98 \% \mathrm{RH}$, $\mathrm{KCl}$ for $84 \% \mathrm{RH}, \mathrm{NaCl}$ for $75 \% \mathrm{RH}$, and $\mathrm{MgCl}_{2} \cdot 6 \mathrm{H}_{2} \mathrm{O}$ for $33 \% \mathrm{RH}$ (Solomon, 1951). Humidities were controlled with a hygrometer at a resolution of $1 \%$ (measuring range at $25^{\circ} \mathrm{C}$ : between 2 and $98 \%$ ), and the actual humidity in the chambers was observed to vary in between $2 \%$ of the expected values. A steep gradient only occurred in the connecting tubes. All assays were carried out at $25^{\circ} \mathrm{C}$ in a temperature-controlled room.

Prior to each assay, the test chambers without the saline solutions were connected to a large laboratory colony and approximately thirty workers were allowed to enter the containers and to inspect the complete 
arrangement. This was essential to provide the chambers with colony odors, in order to avoid alarm behaviors by the workers during the assays. After one hour, the connection with the colony was cut and all workers were collected and returned to the nest. The saline solutions were then placed in the dishes and the conditions were allowed to equilibrate for 1.5 hours before the gardening workers and fungus were introduced into the test chambers. Gardening workers and fungus were collected from regions of high fungal productivity, recognized by the small vegetation particles freshly implanted on the garden. For this purpose, the cover of a large nest chamber was removed and once the colony had calmed, eight minor workers ranging between 3 and $5 \mathrm{mg}$ were gently removed with forceps. Only those workers that were observed to be engaged in implanting vegetation particles into the garden or licking them were collected.

Each assay was initiated by placing 2 gardening workers plus a small fungus garden of ca. $20 \mathrm{mg}$ (approximately $60 \mathrm{~mm}^{3}$ ) in each of the four test chambers. Sliding doors provided in the interconnecting tubes were closed, thus allowing workers to adapt to the new conditions for 10 minutes. Thereafter, the sliding doors separating the single test chambers were opened and the distribution of both workers and fungus gardens was recorded after $45 \mathrm{~min}$. A total of 10 independent assays were performed, each one using new workers and fungus. The results were pooled and expressed as the mean and standard deviation of the relative distributions in the test chambers, both for workers and fungus.

\section{Results and discussion}

During the assays, workers were observed to pick up the fungus gardens and walk around for several minutes before placing them in one of the chambers with a specific humidity. While the distribution of the workers in the test chambers could not be statistically distinguished from a random pattern (Fig. 1, below; $\chi^{2}=7.3, \mathrm{df}=3, \mathrm{p}=0.07$, NS; Chi-square test for goodness of fit to the ratio $1: 1: 1: 1$ ), the fungus gardens were accumulated at the highest humidity offered $(98 \% \mathrm{RH})$ (Fig. 1, above; $\chi^{2}=54.6, \mathrm{df}=3, \mathrm{p}<0.001$ ). The slight tendency in workers to distribute themselves in the chamber with the highest humidity (Fig. 1, below), i.e., the chamber with most of the fungus, is the result of some workers spending time tending and joining the different garden fragments.

Workers were observed to differentiate between low and high humidity and to distinguish the two humid environments which differed by only $14 \%$, since the choices of $84 \%$ $\mathrm{RH}$ for fungus location did not differ from a random pattern. This result clearly indicates that workers were able to sense differences in relative humidity, yet their discrimination was only exhibited when they engaged in fungus culturing. The workers' responsiveness within 45 minutes and their marked preference for $98 \% \mathrm{RH}$ are probably due to the fungus' higher susceptibility to desiccation, suggesting that workers attempt to maximize fungal growth. A similar phenomenon, but related to the relocation of brood, was described in nurse workers of Solenopsis ants: while workers alone did not exhibit any humidity preference, brood-tending workers selected saturated atmospheres to locate larvae and pupae (Potts et al., 1984).

It is worth mentioning that the conditions offered in the experimental arrangement, i.e., stable humidity values inside a given test chamber, may contrast with the situation observed in large Atta-nests in the field. Inflow of air as a consequence of nest ventilation may cause variations in the

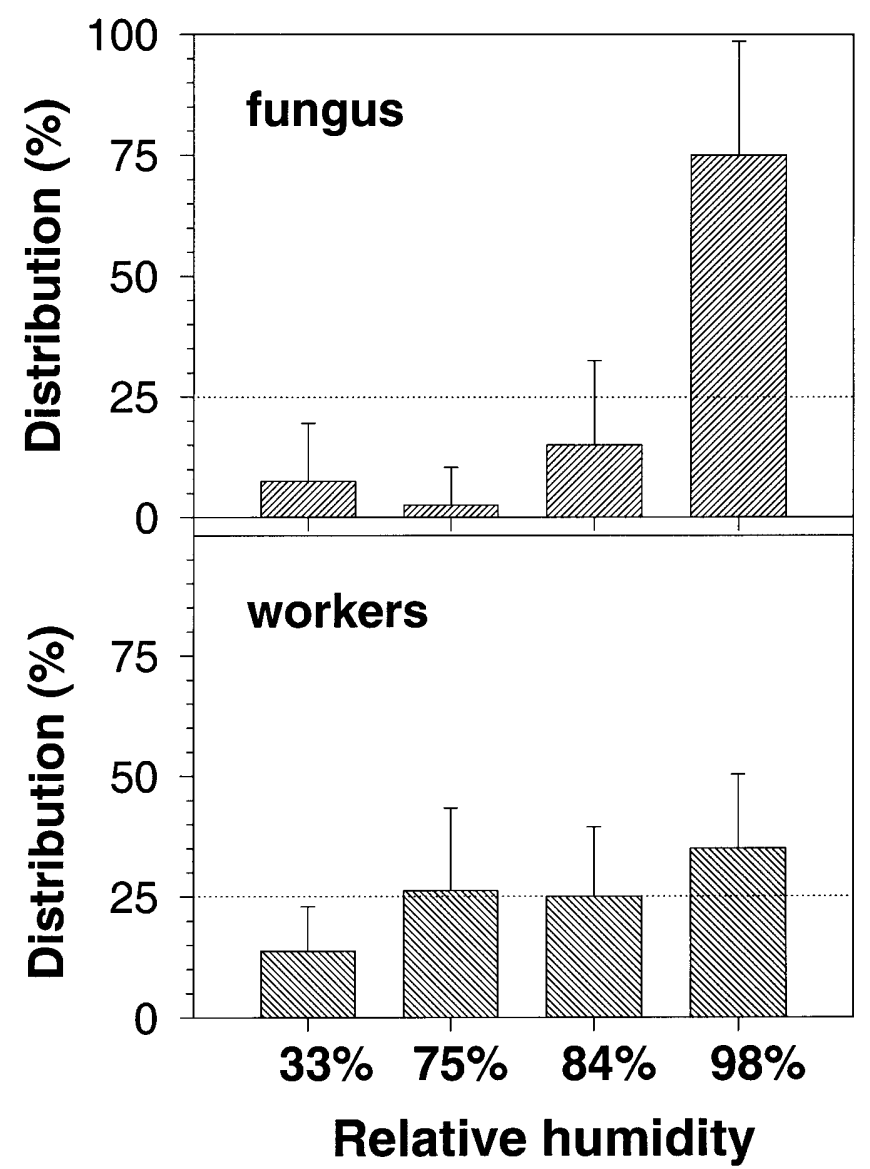

Figure 1. Hygropreference of workers for fungus culturing and for themselves in test chambers under different humidities. Data correspond to means and standard deviation of 10 independent assays. The horizontal lines indicate values expected under random distribution ( $25 \%$ of the responses)

humidity conditions of the fungus chambers. Measurements in mature Atta-nests of two different species, however, indicate that the relative humidity in the area of the fungus chambers was always above $90 \%$, so that the ventilation demands of the colony do not compromise the humidity conditions inside the nest (Atta sexdens, Stahel and Geijskes (1940); Atta vollenweideri, Kleineidam and Roces (2000)). Previous measurements by Eidmann (1935), showing that the relative humidity in the $A$. sexdens fungus chambers ranges from 53 to $57 \%$, are probably erroneous, since gardens maintained in the lab at such low humidities desiccate very rapidly (Stahel and Geijskes, 1940).

The observation that the fungus chambers in different field nests of several leaf-cutting ant species are located deeper in dry soils than in more humid ones (Escherich, 1929; Eidmann, 1935; Weber, 1957) emphasizes the importance of humidity requirements for fungal growth, even for large colonies with elaborated nest architecture and therefore more stable microclimatic conditions. The relocation responses following the humidity demands of the fungus are expected to be more significant for young colonies, which 
have been observed to locate their first fungus chambers up to $3 \mathrm{~m}$ below the surface (Eidmann, 1935), and also for attine ant species constructing more simple or exposed nests (Navarro and Jaffé, 1985; Mueller and Wcislo, 1998). In fact, colonies of the grass-cutting ant Acromyrmex landolti were observed to excavate new chambers during the dry season to depths where soil moisture asymptotically approached a maximum level (Lapointe et al., 1998).

Our results indicate that gardening workers, even though indifferent in their hygropreference for themselves, select appropriate nest environments for their fungus, based solely on its humidity demands. Relocation of fungus gardens to promote their growth, like the repotting of flowering plants by humans, clearly illustrates the skill of leaf-cutting ants as true "gardeners". Beside temperature and carbon dioxide concentration (Kleineidam and Roces, 2000), humidity therefore seems to represent one of the relevant variables that underlay the evolution of regulatory responses for the control of fungus growth in leaf-cutting ants.

\section{Acknowledgments}

This research was supported by funds from a PWA-Program (DAAD, Germany, and Fundación Antorchas, Argentina), and by the Deutsche Forschungsgemeinschaft (grant SFB 251/TP C7, and a fellowship to CK from Graduiertenkolleg "Arthropodenverhalten" of the University of Würzburg). We are indebted to J. Blatt for help with preliminary experiments, and to P. Schilman, J.A. Núñez and A. Weidenmüller for comments on the manuscript.

\section{References}

Autuori, M., 1942. Contribuição para o conhecimento da saúva (Atta spp. Hymenoptera - Formicidae). III. Excavação de um saúveiro (Atta sexdens rubropilosa Forel, 1908). Arq. Inst. Biol. 13: 137-148.

Eidmann, H., 1935. Zur Kenntnis der Blattschneiderameise Atta sexdens L., insbesondere ihrer Ökologie. Z. angew. Entomol. 22: 185-436.

Escherich, K., 1929. Einige Notizen über die Lebensweise, wirtschaftliche Bedeutung und Bekämpfung der Blattschneiderameisen (Atta). Zool. Anz. 82: 185-197.

Kleineidam, C. and F. Roces, 2000. Carbon dioxide concentrations and nest ventilation in nests of the leaf-cutting ant Atta vollenweideri. Insectes soc. 47: 241-248.

Lapointe, S.L., M.S. Serrano and P.G. Jones, 1998. Microgeographic and vertical distribution of Acromyrmex landolti (Hymenoptera: Formicidae) nests in a neotropical savanna. Environ. Entomol. 27: 636-641.

Mueller, U.G. and W.T. Wcislo, 1998. Nesting biology of the fungusgrowing ant Cyphomyrmex longiscapus Weber (Attini, Formicidae). Insectes soc. 45: 181-189.

Navarro, J.G. and K. Jaffé, 1985. On the adaptive value of nest features in the grass-cutting ant Acromyrmex landolti. Biotropica 17: $347-$ 348.

Potts, L.R., O.F. Francke and J.C. Cokendolpher, 1984. Humidity preferences of four species of fire ants (Hymenpotera: Formicidae: Solenopsis). Insectes soc. 31: 335-339.

Powell, R.J. and D.J. Stradling, 1986. Factors influencing the growth of Attamyces bromatificus, a symbiont of attine ants. Trans. Brit. Mycol. Soc. 87: 205-213.

Quinlan, R.J. and J.M. Cherrett, 1978. Aspects of the symbiosis of the leaf-cutting ant Acromyrmex octospinosus (Reich) and its food fungus. Ecol. Entomol. 3: 221-230.

Roces, F. and J.A. Núñez, 1995. Thermal sensitivity during brood care in workers of two Camponotus ant species: circadian variation and its ecological correlates. J. Insect Physiol. 41: 659-669.

Solomon, M.E., 1951. Control of humidity with potassium hydroxide, sulphuric acid, or other solutions. Bull. Entomol. Res. 42: 543-554.

Stahel, G. and D.C. Geijskes, 1940. Observations about temperature and moisture in Atta-nests. Rev. Entomol. 11: 766-775.

Weber, N.A., 1957. Dry season adaptations of fungus-growing ants and their fungi. Anat. Rec. 128: 638. 